\title{
Stimulus control of immunization against chronic learned helplessness
}

\author{
JOSEPH R. TROISI II, PHILIP J. BERSH, MICHAEL F. STROMBERG, \\ and BENJAMIN C. MAURO \\ Temple University, Philadelphia, Pennsylvania \\ and \\ WAYNE G. WHITEHOUSE \\ University of Pennsylvania School of Medicine, Philadelphia, Pennsylvania
}

\begin{abstract}
Two experiments investigated the effectiveness of multiple (five) sessions of signaled escapableshock pretraining in preventing (immunizing against) the shock-escape impairment produced by an equal number of sessions of signaled inescapable shock. In Experiment 1, rats were exposed to 50 pairings per session of a white-noise stimulus with escapable shock during the immunization phase. Subsequently, they were exposed to 50 pairings per session of a different (houselight) stimulus with inescapable shock. Shock-escape performance in a shuttlebox test with constant illumination revealed no evidence of immunization relative to the performance of rats given five prior sessions of light-signaled inescapable shock only. Experiment 2 was identical in all respects to Experiment 1, except that both the escapable- and the inescapable-shock phases for animals in the immunization treatment group involved the same stimulus (houselight) as a shock signal. Under these circumstances, the prior escapable-shock training significantly reduced the shuttlebox escape deficit engendered by chronic exposure to signaled inescapable shock; performance in the shuttlebox was not reliably different from that of rats exposed to signaled escapable shock alone. These findings suggest that, under chronic conditions, the development of stimulus control using Pavlovian conditioning procedures may serve to modulate the normally prophylactic influence on later shock-escape acquisition of serial exposure to escapable and inescapable shocks.
\end{abstract}

Animals exposed to uncontrollable aversive events, such as inescapable electric shock, exhibit major behavioral and physiological aftereffects (see reviews by Maier, 1984; Maier \& Seligman, 1976; Weiss et al., 1981). Prominent among these is a pronounced deficit in the subsequent acquisition of responses to escape shock. Because shockescape impairment is typically not observed in animals given equivalent exposure to escapable shock, it appears to be a consequence of experience with uncontrollability. One well-known account of this effect is provided by learned helplessness theory (Maier \& Seligman, 1976). According to this view, animals exposed to inescapable shock learn that their behavior is independent of shock termination. This learning may then generalize to other situations involving shock, where it is presumed to decrease motivation to escape and lower the animal's sensitivity to the response-reinforcer contingency.

The notion that learning about the relationship between behavior and outcomes may affect the acquisition of later

This research was supported in part by Grant MH42774 from the National Institute of Mental Health, U.S. Public Health Service, and in part by a grant from the Institute for Experimental Psychiatry Research Foundation. J. R. Troisi is now at the Behavioral Pharmacology Research Unit, Department of Psychiatry, Johns Hopkins University School of Medicine. Requests for reprints should be addressed to Philip J. Bersh, Department of Psychology, Temple University, Philadelphia, PA 19122. operant responses suggests a means to prevent ("immunize against") the interference effect of exposure to inescapable shock. A general strategy is to hinder the animal's learning of response-outcome independence during exposure to inescapable shock by exposing the animal to an earlier series of trials during which shock termination is contingent upon responding. That is, if the organism first learns a contingency between its behavior and shock termination, then subsequent exposure to inescapable shock may not produce interference. Evidence for the effectiveness of prior escapable-shock training in immunizing against the adverse impact of inescapable shock on later shock-escape performance was first reported by Seligman and Maier (1967), using dogs as subjects, and later by Seligman, Rosellini, and Kozak (1975), using rats.

Williams and Maier (1977) also obtained evidence of an ameliorative effect of prior exposure to escapable shock under circumstances in which different responses were required and different contexts were utilized during the immunization and test phases. The findings of their study suggest that the immunizing effect of escapable-shock training is fairly general and involves more than contextual mediation or specific response transfer. Similarly, Kirk and Blampied (1986) found that both passive and active shock-escape pretraining effectively blocked the usual escape impairment consequences of later inescapable shock, again highlighting the apparently greater impor- 
tance of prior control over shock, relative to motor transfer effects. Furthermore, other consequences of exposure to inescapable shock, such as the reinstatable analgesic reaction, also appear to be mitigated by prior exposure to escapable shock (Moye, Coon, Grau, \& Maier, 1981). There is even evidence that concurrent partial control (i.e., control over an aversive characteristic of inescapable shock) is sufficient to prevent later escape impairment. Alloy and Bersh (1979) found that rats that could control the intensity of otherwise inescapable shocks showed no subsequent escape impairment, whereas yoked animals exposed to identical shocks, but with no control even over intensity, manifested significant escape deficits. Thus, the evidence for amelioration of the consequences of exposure to inescapable shock by earlier or concurrent exposure to escapable shock is substantial.

Typically, the induction of a learned helplessness effect is accomplished by exposing animals to a single session of inescapable shock. Recent work in our laboratory (Bersh, Whitehouse, Blustein, \& Alloy, 1986) suggests, however, that, with more protracted exposure to inescapable shock (i.e., nine sessions), the escape interference effect diminishes significantly, unless the shocks are signaled and the signal is also present during the later escape acquisition test. In this research, the magnitude of subsequent shock-escape impairment was an increasing function of the extent to which inescapable shocks were signaled during the training sessions. No effect of varying the correlation between signal and shock was found for the escapable-shock rats to which the inescapable-shock animals were yoked. This suggests that, with chronic shock exposure, signaling shock produces later escape impairment exclusively in the case of a zero-operant contingency. The fact that escape interference was obtained only if the prior inescapable-shock signal was present during the test suggests that stimulus control had developed over the behavioral consequences of inescapable shock. In contrast to these findings for chronic exposure to inescapable shock, rats exposed to only a single session of inescapable-shock manifested escape impairment without regard to the signaling condition during training (Bersh et al., 1986, Experiment 2).

In view of the results reported by Bersh et al. (1986), there is reason to suggest that immunization against the escape impairment effects of chronic exposure to signaled inescapable shock may depend on more than simple prior experience with a shock-escape contingency. Variables affecting stimulus control by the shock signal might also play an important role in immunization. The two experiments that follow investigate this question.

\section{EXPERIMENT 1}

In Experiment 1, we attempted to determine whether immunization would occur in the chronic situation, despite the fact that different stimuli were used to signal shocks during the escapable-shock (i.e., immunization) and inescapable-shock phases. Both learned helplessness theory
(Maier \& Seligman, 1976) and the findings of Williams and Maier (1977) suggest that exposure to escapable shock may be sufficient to alleviate shock-escape interference produced by subsequent exposure to inescapable shock. On the other hand, if the differential consequences of escapable and inescapable shock are subject to stimulus control, interference with shock escape may occur in the presence of the stimulus paired with inescapable shock, despite prior exposure to differently signaled escapable shock.

\section{Method}

Subjects. Forty-eight naive male rats (Holtzman strain), weighing between 350 and $400 \mathrm{~g}$ at the beginning of the experiment, served as subjects. All animals were housed in individual cages that provided free access to food and water.

Apparatus. Training occurred in six identical Lehigh Valley Electronics experimental chambers; there were two sets of three experimental chambers, allowing two triads to run concurrently. The side walls and ceilings were made of clear Plexiglas. The front and rear walls were made of stainless steel, as was the grid floor. The chamber was $30.2 \mathrm{~cm}$ long, $24 \mathrm{~cm}$ wide, and $36.8 \mathrm{~cm}$ high. A stainless steel lever, requiring a force of approximately $10 \mathrm{~g}(1.0 \mathrm{~N})$ to depress and measuring $2.7 \mathrm{~cm}$ wide and $0.3 \mathrm{~cm}$ thick, protruded through the front wall, $3.0 \mathrm{~cm}$ above the grid floor and $3.5 \mathrm{~cm}$ from the left side wall. Sixteen stainless steel grid bars, measuring $0.5 \mathrm{~cm}$ in diameter, were spaced $1.8 \mathrm{~cm}$ apart (center to center) and were mounted perpendicular to the side walls. Electric shock of $1.2 \mathrm{~mA}$ intensity was supplied to the grid floors of each chamber by separate Coulbourn Instruments E13-16 shocker/distributors. Directly above the lever, mounted on the ceiling, was a speaker, measuring approximately $9.0 \mathrm{~cm}$ in diameter. Adjacent to the speaker, in the center of the ceiling, was a 7-W houselight. Programmed events were arranged by electromechanical equipment located in an adjacent room.

Escape testing occurred in a Lehigh Valley two-way shuttlebox $(46.0 \times 19.0 \times 22.5 \mathrm{~cm})$ with Plexiglas side walls and ceiling and stainless steel walls. A stainless steel partition with a $6.0 \times 7.0 \mathrm{~cm}$ rounded archway divided the shuttlebox into two equal-sized compartments. The floor of each compartment consisted of 20 stainless steel grids, $0.3 \mathrm{~cm}$ in diameter and spaced $0.95 \mathrm{~cm}$ apart Constant-current shocks of $0.6-\mathrm{mA}$ intensity were supplied by a Coulbourn Instruments E13-16 shocker/distributor. Crossings by subjects between compartments were detected by microswitches in contact with the tilt floor. The shuttlebox was housed in a soundattenuating chamber equipped with a ventilating fan. Programming and data collection were accomplished by electromechanical equipment located in an adjacent room.

Procedure. The animals were randomly assigned to one of three groups. For the animals receiving the immunization treatment (Group ES-IS), the first five sessions involved exposure to escapable shocks. Each of these sessions consisted of 50 shocks of 1.2-mA intensity, which were preceded by a 5-sec, 80-dB (re SPL) whitenoise stimulus that terminated with the onset of shock. The mean intershock interval was $60 \mathrm{sec}$, with a range from $10-110 \mathrm{sec}$. On a given trial, the shock remained on for $30 \mathrm{sec}$, unless the animal pressed the response lever after an initial 2 -sec interval during which responding was ineffective. On the sixth session, a 5-day inescapable-shock phase was instituted for Group ES-IS. Concurrently, two additional groups of animals (i.e., ES and IS) were added to form yoked triads. Shocks administered to members of each triad were preceded by a 5-sec illumination of the chamber houselight, but, otherwise, had the same characteristics as shocks delivered to the ES-IS animals in the previous phase of training. The ES animals received escapable shock; shock for the entire triad was terminated when the response lever was pressed after the 2-sec minimum shock interval elapsed. Responses by the ES-IS and IS animals had no 
effect on shock termination; hence, shocks for the latter groups were inescapable.

Twenty-four hours after the final training session, the shockescape test was conducted. During the first five trials, shock terminated when the animal crossed from one compartment of the shuttlebox to the other (FR 1). Following the last FR 1 trial, 30 FR 2 trials (i.e., requiring crossing to the other compartment and returning) commenced. All shocks had a maximum duration of $60 \mathrm{sec}$ and were presented, unsignaled, at variable intervals $(M=60 \mathrm{sec} ;$ range $=10-110 \mathrm{sec})$. The shuttlebox was illuminated continuously during the test phase.

\section{Results}

Training. All ES-IS animals acquired the leverpress response and escaped shock on virtually every trial during the initial five escapable-shock sessions. The mean escape latency, measured from the end of the 2-sec minimum shock interval, was $2.5 \mathrm{sec}$, which was not significantly different from the 2.0 -sec mean latency of the ES animals over the final five sessions $[t(30)=1.08, p>.10]$. When shifted to the inescapable-shock phase of training, the animals in the ES-IS group continued to leverpress during shocks. The mean number of responses declined systematically over sessions from 144 responses during the first inescapable-shock session to 70 responses during the last session.

Test. Shuttlebox shock-escape performance was evaluated in terms of three dependent measures: FR 1 escape latency, FR 2 escape latency, and number of failures to escape shock. Due to heterogeneity of variance in each measure, the data were submitted to a log transformation prior to analysis.

There were no reliable differences among the three treatments in terms of latency to perform the FR 1 es- cape response $[F(2,45)=1.48, p>.10]$. On the other hand, reliable intergroup differences were apparent when the more effortful FR 2 escape requirement was introduced $[F(2,45)=3.52, p<.05]$. As illustrated in Figure 1 , and confirmed by Newman-Keuls post hoc comparisons, the animals in Groups IS and ES-IS performed comparably. The difference between the ES and IS animals was significant, whereas that between the ES and ES-IS animals was marginally reliable $(p=.066)$. An analysis of the number of failures to escape shock $[F(2,45)=4.70$, $p<.05]$ revealed significant differences between the ES group and both the ES-IS group $(p<.02)$ and the IS group $(p<.03)$.

\section{Discussion}

The animals that were preexposed to 5 days of escapable shock followed by 5 days of inescapable shock showed as much interference with shuttlebox escape acquisition as did the animals exposed to inescapable shock only. Thus, preexposure to five sessions of escapable shock was insufficient to immunize the ES-IS animals against the effects of subsequent equal exposure to inescapable shock. There are at least three possible explanations for the failure of immunization in this experiment. One possibility is that the shuttlebox test occurred in the presence of a stimulus (i.e., continuous houselight illumination) that was used, in the second phase of ES-IS training, as a discrete signal for inescapable shock. This may mask the efficacy of prior training with escapable shock because the inescapable-shock signal is capable of eliciting behavior (alternatively, "expectancy of response ineffectiveness" or physiological mediators) appropriate to a situation involving inescapable shock, which may lead

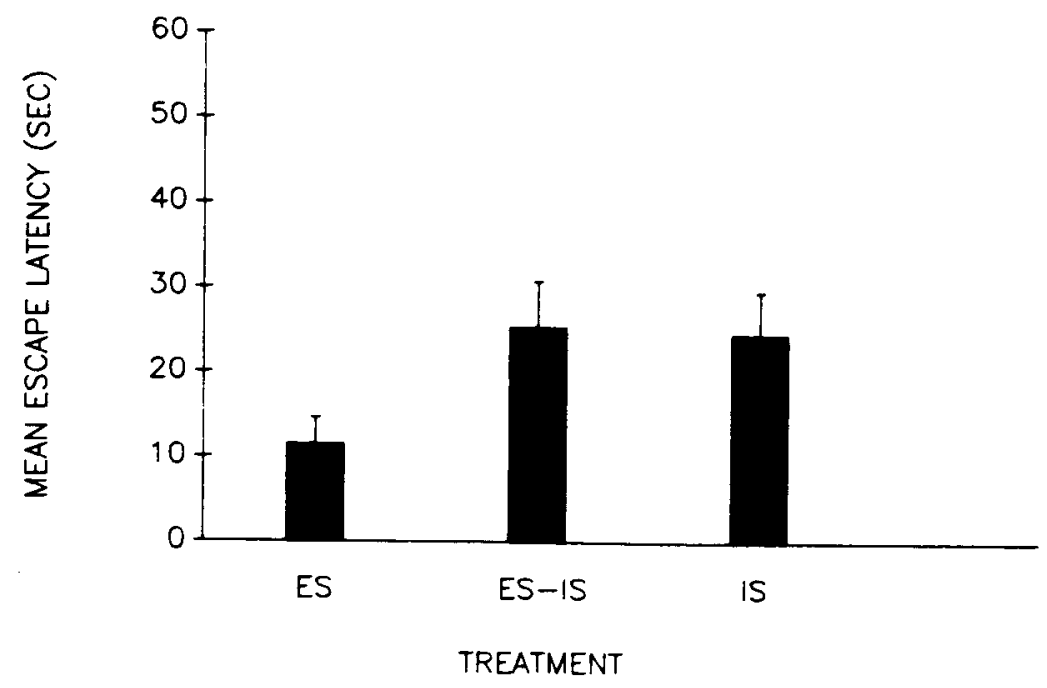

Figure 1. Mean shock-escape latency during FR 2 trials in an illuminated shuttlebox. $\mathrm{ES}=$ five sessions of light-signaled escapable-shock training; ES-IS = five sessions of noise-signaled escapable-shock training, followed by five sessions of exposure to light-signaled inescapable shocks; IS = five sessions of exposure to light-signaled inescapable shocks. In all cases, the final training session occurred $24 \mathrm{~h}$ prior to the st.uttlebox test. 
to deficits in escape performance. This suggests that if the escapable-shock signal, rather than the inescapableshock signal, had been present during the test, there would have been a significant reduction or elimination of shockescape impairment. Unfortunately, the findings of Bersh et al. (1986) imply that, without the presence of the prior inescapable-shock signal during the test, escape impairment would not be found. Thus, under chronic training conditions, a valid assessment of the immunizing influence of preexposure to escapable shock requires the presentation of the inescapable-shock signal, in some form, during the shuttlebox test.

The second possibility concerns the fact that the ES-IS animals were exposed to 10 days of shock (i.e., 5 days of escapable shock followed by 5 days of inescapable shock). That is, the failure of escapable-shock training to immunize against chronic exposure to signaled inescapable shock may have been due to the cumulative effect of exposure to 500 shocks, or perhaps exposure to 250 inescapable shocks may have overcome any immunizing effect of prior exposure to an equal number of escapable shocks. Finally, it is possible that the immunizing effect of prior escapable-shock exposure was substantially under the control of the noise stimulus, so that its influence upon the effect of light-signaled inescapable shocks was weakened because the noise was absent during that phase of training.

\section{EXPERIMENT 2}

In Experiment 2, the same stimulus (light) signaled both escapable and inescapable shock for the animals in the immunization treatment group. If the failure to obtain immunization in Experiment 1 was due to total shock exposure or to the chronic, though equal, exposure to inescapable shock following preexposure to escapable shock, the use of a common shock signal for the two phases should do nothing to alter that outcome. On the other hand, if providing different signals for escapable and inescapable shock significantly reduced the mitigating influence of escapable-shock training upon later inescapableshock exposure, then the use of the same signal should be more effective in producing immunization.

\section{Method}

Subjects. Forty-eight naive male rats (Holtzman strain), weighing between $350-400 \mathrm{~g}$ at the start of the experiment, served as subjects. All animals were housed individually and maintained on ad-lib food and water during the course of the experiment.

Procedure. Experiment 2 was procedurally identical to Experiment 1, except that the same 5-sec houselight stimulus was used to signal shocks in both the escapable- and inescapable-shock phases for Group ES-IS. Each phase was carried out for five sessions. The comparison groups, ES and IS, received only five sessions of training with light-signaled escapable shock and inescapable shock, respectively. Testing again occurred in an illuminated shuttlebox.

\section{Results and Discussion}

Training. Leverpress escape responding was acquired by all of the ES-IS animals during the first five escapable- shock sessions. The mean latency over these sessions was $1.7 \mathrm{sec}$, which was not reliably different from the 2.4-sec mean escape latency of the ES animals during the final five sessions $[t(30)=1.41, p>.10]$. As in Experiment 1 , the ES-IS animals continued to make leverpress responses during shocks when the inescapable-shock sessions were administered. During the first inescapable-shock session, a mean of 200 such nonreinforced responses occurred; by the fifth session, the number of leverpresses during shocks had decreased to 47 .

Test. Analyses were conducted on three measures of shuttlebox escape performance: FR 1 latency, FR 2 latency, and number of failures to escape shock. As in Experiment $1, \log$ transformations were required to eliminate heterogeneity of variance in the data prior to statistical analysis.

Escape latencies during FR 1 trials varied across the three conditions $[F(2,45)=6.86, p<.01]$. NewmanKeuls post hoc tests revealed that the animals in the ES group had significantly shorter latencies than did those in the IS group $(p<.01)$, whereas the subjects in Group ES-IS had intermediate latencies, not quite significantly different from either of the other groups (both ps $<.08)$.

Figure 2 depicts the mean escape latencies of the three treatment groups for FR 2 trials of the shuttlebox test. As is evident from the figure, reliable intergroup differences in performance occurred $[F(2,45)=6.71, p<.01]$. Newman-Keuls comparisons indicated that the animals in Group ES escaped shock significantly faster than did their counterparts in Group IS $(p<.01)$. Importantly, the animals in Group ES-IS also had significantly shorter latencies than did the IS animals $(p<.05)$ and did not differ from the ES animals. This same pattern of results was obtained for number of escape failures during the shuttlebox test $[F(2,45)=8.10, p<.001]$.

These findings indicate that immunization against the escape impairment consequences of exposure to inescapable shock is not limited to an acute (i.e., one session) preparation, but that it can also be demonstrated in the chronic case. The only procedural change from Experiment 1 was the use of the same signal for escapable- and inescapable-shock phases for the immunization treatment group. Accordingly, these results rule out an interpretation of the failure to immunize in Experiment 1 based on either the total number of shocks to which the ES-IS animals were exposed or the chronicity of inescapableshock exposure. Instead, they suggest strongly that the immunization failure in Experiment 1 resulted from the use of different signals for escapable and inescapable shock.

\section{GENERAL DISCUSSION}

Previous research has demonstrated that prior exposure of animals to escapable shock immunizes against the shockescape impairment that otherwise follows exposure to inescapable shock (e.g., Seligman \& Maier, 1967; Seligman et al., 1975; Williams \& Maier, 1977). In those experi- 


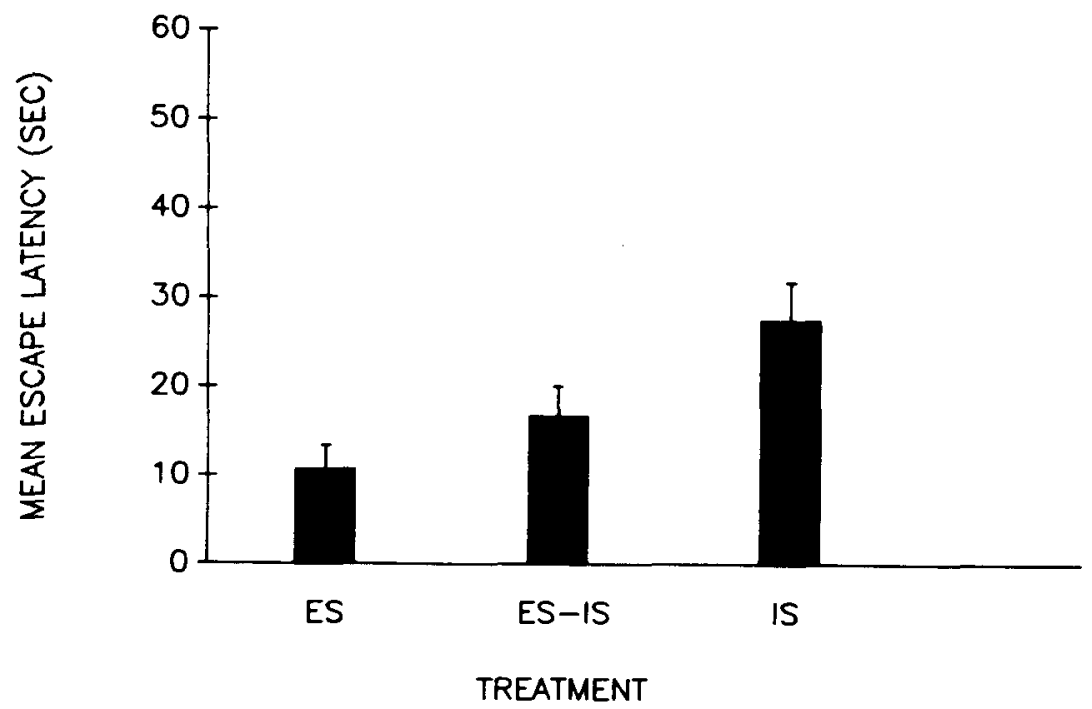

Figure 2. Mean shock-escape latency during FR 2 trials in an illuminated shuttlebox. ES = five sessions of light-signaled escapable-shock training; ES-IS = five sessions of light-signaled escapable-shock training, followed by five sessions of exposure to lightsignaled inescapable shocks; IS = five sessions of exposure to light-signaled inescapable shocks. In all cases, the final training session occurred $24 \mathrm{~h}$ prior to the shuttlebox test.

ments, escapable- and inescapable-shock exposure were each limited to a single session. The present experiments involved multiple-session (chronic) exposure to shock.

The results of Experiment 1 indicate that, when exposure is chronic, pretraining with escapable shock may fail to immunize against the effects of equal exposure to inescapable shock. The data of Experiment 2 strongly support the view that this is attributable to the use of different signals for escapable and inescapable shock in Experiment 1 . Under otherwise identical training and test conditions, the Group ES-IS animals in Experiment 2 were exposed to same-signaled escapable and inescapable shock. Their test performance was significantly better than that of the animals preexposed only to inescapable shock, and it was not reliably worse than that of the animals preexposed only to escapable shock. It is also clear from the results of Experiment 2 that immunization failure in Experiment 1 was due neither to total shock exposure for the Group ES-IS animals, relative to Groups ES and IS, which received less shock exposure, nor to the chronicity of inescapable-shock exposure that followed their escapableshock training. Such modulation by signaling of the effects of an otherwise identical immunization procedure is consistent with the role of signaling in determining the magnitude of shock-escape impairment produced by chronic exposure to inescapable shock only (Bersh et al., 1986; Bersh, Whitehouse, Laurence, Blustein, \& Alloy, 1990).

In the present study, the change from the different-signal condition to the same-signal condition is confounded with the change from noise to light as the signal for escapable shock in the immunization phase. This raises the question as to whether or not these data might represent a sensory modality effect. Such effects have been reported as critical, for example, in determining the effectiveness of a shock-termination feedback signal in preventing shockescape impairment after one session of inescapable-shock exposure (Jackson \& Minor, 1988). Clearly, such an issue can only be resolved categorically by further research. However, there is every reason to believe that immunization would also have failed if the roles of the noise and light in Experiment 1 had been reversed. There is substantial evidence to support the superiority of an auditory stimulus over a visual stimulus for Pavlovian excitatory conditioning involving shock as the unconditional stimulus (US; see Jacobs \& LoLordo, 1980; LoLordo \& Jacobs, 1983; LoLordo, Jacobs, \& Foree, 1982). Indeed, this suggests that chronic exposure to noise-signaled inescapable shock only would subsequently produce more severe shock-escape impairment in the presence of noise than equal exposure to light-signaled inescapable shock would subsequently produce in the presence of light. Accordingly, light-signaled escapable shock should be even less effective in immunizing against noise-signaled inescapable shock than when the roles of the two signals are reversed, as in Experiment 1.

In both experiments, the test was conducted in an illuminated shuttlebox. Light was a unique signal for inescapable shock in Experiment 1, but it was the common signal for escapable and inescapable shock in Experiment 2. It is reasonable to assume that a unique signal for inescapable shock should produce greater shockescape impairment than should a signal with a history of correlation with escapable, as well as inescapable, shock. This suggests that, in Experiment 1, the presence, during the test, of the escapable-shock signal (noise), rather than the inescapable-shock signal, would have produced 
evidence of immunization. However, under these hypothetical circumstances, the presence of noise would be confounded with the absence of the inescapable-shock signal. As Bersh et al. (1986) found, following chronic preexposure to light-signaled inescapable shock, escape deficits were eliminated when the test was carried out in a dark shuttlebox. It is, of course, possible that a compound of light and noise during the test would have reduced or eliminated the shock-escape impairment induced by light alone, an effect more appropriately labeled therapy (Maier \& Seligman, 1976).

An alternative interpretation is based on the influence of signaled escapable-shock pretraining on Pavlovian conditioning to a signal reinforced by inescapable shock. Presumably, escapable shock pretraining with a different signal should interfere less with subsequent conditioning to an inescapable-shock signal than should pretraining with the same signal. Indeed, the difference in sensory modality of the signals for escapable and inescapable shock in Experiment 1 may have resulted in the same magnitude of conditioning to the light by inescapable shock for the Group ES-IS animals as for the Group IS animals. Shock-escape impairment may have occurred for the Group ES-IS animals in Experiment 1, but not for those in Experiment 2, because of differences in Pavlovian conditioning to the light during inescapable-shock exposure, not because of the uniqueness of the light as a signal for inescapable shock during the test.

In some respects, it is more difficult to account for the success of immunization in Experiment 2 than for its failure in Experiment 1. Why should prior reinforcement of a light by escapable shock interfere with later Pavlovian conditioning to the same light with inescapable shock as the US? Presumably, escapable-shock reinforcement would have resulted in some conditioning, particularly in view of the fact that escape was possible only after $2 \mathrm{sec}$ of shock exposure. Thus, later conditioning to the light with inescapable shock as the US ought to have been facilitated. On the other hand, there is evidence that escapability may reduce Pavlovian conditioning with a shock US (e.g., Desiderato \& Newman, 1971; Mineka, Cook, \& Miller, 1984), perhaps because the proprioceptive feedback from the escape response develops inhibitory properties (Mineka et al., 1984; Starr \& Mineka, 1977). This would mean that prior exposure to light-signaled escapable shock would have little influence on subsequent conditioning to the light by inescapable shock. In either case, however, Pavlovian conditioning to the light during inescapable shock in Experiment 2 should have been at least as great for Group ES-IS as for Group IS, so that its shock-escape performance during the test should have been equally impaired.

It is possible that conditioning to the light during the inescapable-shock phase of Experiment 2 was retarded for the ES-IS animals because of the availability of the former escape response (i.e., leverpressing), which, of course, was no longer negatively reinforced. Nevertheless, leverpresses during light presentations or during inescapable shocks may have provided inhibitory conditional proprioceptive stimuli (cf. Mineka et al., 1984) that attenuated the acquisition of further excitation by the light. Of course, leverpresses were also free to occur among the ES-IS subjects during the inescapable-shock phase of Experiment 1. However, in the absence of an already-established shock signal (i.e., noise) or of an excitatory context, the inhibitory properties of response-produced stimuli for these animals may have been inadequate to interfere with conditioning to the light. This hypothesis gains support from the fact that the inhibitory strength of a stimulus is proportional to the magnitude of excitation present (Rescorla, 1969; Rescorla \& Wagner, 1972). Therefore, when the same stimulus is used to signal escapable and inescapable shock, the inhibitory stimulus properties of leverpressing should be stronger than when a different shock signal is used in the two phases. A comparison of responding by the ES-IS animals during the inescapable shock phases of the two experiments revealed that the ES-IS subjects in Experiment 2 made more leverpresses than did those in Experiment 1 during the early sessions of inescapableshock exposure, a difference which was statistically significant for the first session. While such differences in responding during inescapable shocks might be expected on the basis of differential stimulus generalization, it should be noted that the foregoing interpretation does not require differences in the number of inescapable-shock responses between the two experiments. Rather, it suggests, primarily, that such responses will have a greater inhibitory effect if the current shock signal has already accrued substantial conditional excitation, as was presumably the case in Experiment 2 .

Alternatively, the present findings may be taken to imply that the character of the conditional response (CR) to a stimulus paired with an escapable shock US is different from, and incompatible with, that which develops with an inescapable-shock US. For example, learned helplessness theory (Maier \& Seligman, 1976) identifies, as the basis for immunization, the development of an expectancy of control during escapable-shock training, which then competes with the formation of the so-called helplessness expectancy during subsequent inescapable-shock exposure. If an expectancy of control develops to the light by virtue of earlier light-escapable-shock pairings, then it should be evoked by the light as well during light-signaled inescapable-shock exposure. This, in turn, should impair the development of the helplessness expectancy and/or its conditionability to the light. ${ }^{1}$ Analogously, evidence that exposure to inescapable shock produces unique behavioral and physiological adaptations (Maier, 1984; Weiss et al., 1981) allows one to substitute into the same scenario competing behavioral and physiological CRs for the cognitive influences borrowed from learned helplessness theory.

A major implication of the present findings is that the effects of exposure to escapable shock, like those produced by exposure to inescapable shock, are subject to stimulus control. Previous research (e.g., Bersh et al., 1986; Minor \& LoLordo, 1984) has demonstrated explicit control by 
exteroceptive or contextual stimuli over the adverse consequences of exposure to inescapable shock, whereas there has been no clear evidence of such control over the effects of escapable-shock exposure. Indeed, Bersh et al. (1986) reported a monotonic relationship between the magnitude of the signal-shock contingency during training sessions and the severity of subsequent shock-escape impairment among rats exposed to chronic inescapable shock, whereas no such covariation was apparent for rats given identical escapable-shock exposure. A distinctive feature of the present research, however, was the sequence of escapable shock followed by inescapable-shock training phases, which provided an opportunity to observe an antagonistic influence of the escapable-shock signal on the effects of later inescapable-shock exposure. Accordingly, stimulus control over the effects of exposure to escapable shock may occur generally, especially with chronic treatments, but its manifestation may require circumstances more sensitive than the shock-escape acquisition test routinely employed in learned helplessness experiments.

In view of the significant role for Pavlovian processes implicated by the findings of the present experiments, immunization against chronic learned helplessness would seem to depend critically on the resistance of the prior signal for escapable shock to counterconditioning by the inescapable-shock US. This suggests that with enough subsequent exposure to same-signaled inescapable shock, the immunizing influence of prior signaled escapableshock training may be overcome. The delineation of such parameters remains an important agenda for research on the role of stimulus control in the chronic learned helplessness effect.

\section{REFERENCES}

Alloy, L. B., \& Bersh, P. J. (1979). Partial control and learned helplessness in rats: Control over shock intensity prevents interference with subsequent escape. Animal Learning \& Behavior, 7, 157-164.

Bersh, P. J., Whitehouse, W. G., Blustein, J. E., \& Alloy, L. B. (1986). Interaction of Pavlovian conditioning with a zero operant contingency: Chronic exposure to signaled inescapable shock maintains learned helplessness effects. Journal of Experimental Psychology: Animal Behavior Processes, 12, 277-290.

Bersh, P. J., Whitehouse, W. G., Laurence, M. T., Blustein, J. E., \& AlLOY, L. B. (1990). Signaling the duration of uncontrollable shock impairs subsequent shock-escape. Psychological Record, 40, 113-125.

Desiderato, O., \& Newman, A. (1971). Conditioned suppression produced in rats by tones paired with escapable or inescapable shock. Journal of Comparative \& Physiological Psychology, 77, 427-431.

JACKSON, R. L., \& MINOR, T. R. (1988). Effects of signaling inescapable shock on subsequent escape learning: Implications for theories of coping and "learned helplessness." Journal of Experimental Psychology: Animal Behavior Processes, 14, 390-400.

JACOBS, W. J., \& LoLordo, V. M. (1980). Constraints on Pavlovian aversive conditioning: Implications for avoidance learning in the rat. Learning \& Motivation, 11, 427-455.
KIRK, R. C., \& Blampied, N. M. (1986). Transituational immunization against the interference effect (learned helplessness) by prior passive and active escape. Psychological Record, 36, 203-214.

LoLordo, V. M., \& JACOBS, W. J. (1983). Constraints on aversive conditioning in the rat: Some theoretical accounts. In M. D. Zeiler \& P. Harzem (Eds.), Advances in analysis of behavior (Vol. 3, pp. 325351). Chichester, England: Wiley.

LoLordo, V. M., JACOBS, W. J., \& ForeE, D. D. (1982). Failure to block control by a relevant stimulus. Animal Learning \& Behavior, 10, 183-193.

MAIER, S. F. (1984). Learned iuelplessness and animal models of depression. Progress in Neuro-Psychopharmacology \& Biological Psychiatry, 8, 435-446.

Maier, S. F., \& Seligman, M. E. P. (1976). Learned helplessness: Theory and evidence. Journal of Experimental Psychology: General, 105, 3-46.

Mineka, S., Cook, M., \& Miller, S. (1984). Fear conditioned with escapable and inescapable shock: Effects of a feedback stimulus. Journal of Experimental Psychology: Animal Behavior Processes, 10, 307-323.

Minor, T. R., \& LoLordo, V. M. (1984). Escape deficits following inescapable shock: The role of contextual odor. Journal of Experimental Psychology: Animal Behavior Processes, 10, 168-181.

Moye, T. B., CoOn, D. J., Grau, J. W., \& Maier, S. F. (1981). Therapy and immunization of long-term analgesia in rats. Learning \& Motivation, 12, 133-148.

Rescorla, R. A. (1969). Pavlovian conditioned inhibition. Psychological Bulletin, 72, 77-94.

Rescorla, R. A., \& Wagner, A. R. (1972). A theory of Pavlovian conditioning: Variations in the effectiveness of reinforcement and nonreinforcement. In A. H. Black \& W. F. Prokasy (Eds.), Classical conditioning II: Current theory and research (pp. 64-99). New York: Appleton-Century-Crofts.

Seligman, M. E. P., \& Maier, S. F. (1967). Failure to escape traumatic shock. Journal of Experimental Psychology, 74, 1-9.

Seligman, M. E. P., Rosellini, R. A., \& Kozak, M. (1975). Learned helplessness in the rat: Reversibility, time course, and immunization. Journal of Comparative \& Physiological Psychology, 88, 542-547.

STARR, M. D., \& Mineka, S. (1977). Determinants of fear over the course of avoidance learning. Learning \& Motivation, 8, 332-350.

Warken, D. A., Rosellini, R. A., Plonsky, M., \& DeCola, J. P. (1985). Learned helplessness and immunization: Sensitivity to response-reinforcer independence in immunized rats. Journal of Experimental Psychology: Animal Behavior Processes, 11, 576-590.

Weiss, J. M., Goodman, P. A., Losito, B. G., Corrigan, S., Charry, J. M., \& Bailey, W. H. (1981). Behavioral depression produced by an uncontrollable stressor: Relationship to norepinephrine, dopamine, and serotonin levels in various regions of rat brain. Brain Research Reviews, 3, 167-205.

Williams, J. L., \& MaIER, S. F. (1977). Transituational immunization and therapy of learned helplessness in the rat. Journal of Experimental Psychology: Animal Behavior Processes, 3, 240-253.

\section{NOTE}

1. The possibility of differential control by contextual or other stimuli over expectancies of response-outcome dependence versus independence has been suggested by the dual expectancy hypothesis of Warren, Rosellini, Plonsky, and DeCola (1985).

(Manuscript received February 24, 1990; revision accepted for publication September 11, 1990.) 